\title{
Cultural Rights Education between Use of Heritage and Alphabetical Skills
}

\author{
Antonella Nuzzaci \\ ${ }^{1}$ University of L'Aquila, Italy \\ Correspondence: Antonella Nuzzaci, University of L’Aquila, Italy.
}

Received: May 25, 2020

Accepted: July 13, 2020

Available online: July 22, 2020

doi:10.11114/ijsss.v8i5.4938

URL: https://doi.org/10.11114/ijsss.v8i5.4938

\begin{abstract}
The contribution addresses the problem of the relationship between education for cultural rights, use of cultural heritage and the need for alphabetical skills, focusing on reflection on two elements, the processes of cultural democratization and literacy. The lack of cultural fruition by certain categories of individuals is interpreted in the contribution as a complex aspect of the multi-alphabetic processes, which does not end with the lack of "visit" to the sites and places of culture, but contains within itself the germs of the social and cultural exclusion. The article ends with the importance of activating concrete and incisive forms of education for cultural good based on awareness of use in order to stem the forms of "exclusion" at different levels, to strengthen the cultural profiles of the school population and not, to re-establish individual and social identity and to exercise active citizenship.
\end{abstract}

Keywords: cultural rights education, education, cultural heritage, skills, learning, teaching

\section{Heritage as an "Open Space" of Cultural Democratization}

In the second half of the twentieth century, cultural phenomena diversified in the forms and methods of reception. Beyond the artistic work, traditionally considered as the main reference form of cultural heritage, new types of "good" have emerged over time thus have changed classifications and uses of cultural objects.

The transformation of the conscious use of the "asset" has gradually linked to this transformation, which has progressively provoked a change in the behavior of the population and improved the ways of learning the different types of heritage, as well as the elements connected to it. It therefore happened that the plurality, heterogeneity and diffusion of cultural forms, in an increasingly "globalized space", then called into question the very concept of "heritage" and "gender", as well as "fruition". This change was also determined by the need to consider heritage as a tool to create aware citizens and to feed various forms of democratic citizenship (Baldriga 2020), sensitive to cultural production not only guided by market logic but sufficiently open and responsible that it did not remain defined within delimited times and space (Panciroli \& Macauda, 2017).

The use of the term "heritage", at present, in fact corresponds to a broader and more integrated concept that leads us to speak of "cultural heritages" in the plural grouping within it numerous categories: monuments and sites (archaeological, historical, industrial etc.), oral traditions, works of art, archives, books, cinema, music etc. Furthermore, unlike family or personal heritage, cultural heritage must be transmitted, as a memory of the past, to future generations who have the responsibility to identify it, protect it, safeguard it and increase it.

Bearer of continuity between past, present and future, it contributes to building and strengthening the social ties through which the relationship with the local, national and world community is realized, an expression of the value of the relationship and sharing (Nuzzaci, 2017; 2015). Due to its intrinsic characteristics, it has an origin value (often ancient), a scientific value (authentic), an affective value (bearer of emotion, feelings), a symbolic value (relative to the present), an educational value (constitutes a support for learning), a social value (identity bearer) and a collective value (local, regional, national and global).

The variety of heritage and its diffusion throughout the territory has obviously led over time to the development of diversified teaching and mediation practices aimed at creating new ways of exchange and relationship, as well as cultural appropriation, capable of opening the "good" to a cultural democratization capable of transforming the community (Nuzzaci, 2015). In fact, the practices, representations and expressions of the knowledge and skills that 
communities o groups and, in certain cases, individuals, identify as part of their "heritage" have themselves become "cultural heritage".

The Creative Alliances for Europe Report (Collard \& Witte, 2015) highlights how cultural education is seen as the path to "strengthen our understanding of the value of Europe", enabling people to become "active and constructive citizens of Europe, developing the "capacity to solve problems without violence", the "creativity and resilience to imagine and create a better world" and the "courage to be different and value diversity".

The heritage has therefore gradually characterized itself in an "object" and "non-object", "tangible" and "intangible", "visible" and "invisible", "usual" and "unusual" sense: thought, represented, transmitted by a generation to the other and constantly recreated through communities and groups in response to the environment, interaction with nature and the historical conditions of existence. Think, for example, of the existential displacement that the loss of it can generate in the community in the presence of a natural catastrophe (Nuzzaci, 2018).

Looking at both the intangible heritage, such as traditions and oral expressions, language, rituals, festive events etc., to the material one, such as the artistic, archaeological, science, technical, etc. object, you cannot do without to detect how such forms of heritage have evolved becoming a more common "social practice" characterized by a conscious cultural appropriation that leads towards the acquisition of significant learning capable of affecting reality.

Cultural heritages are understood here as tools for analyzing and interpreting reality, as shown below by the bas-relief Les fugitifs ou les émigrants, by Honoré Daumier.

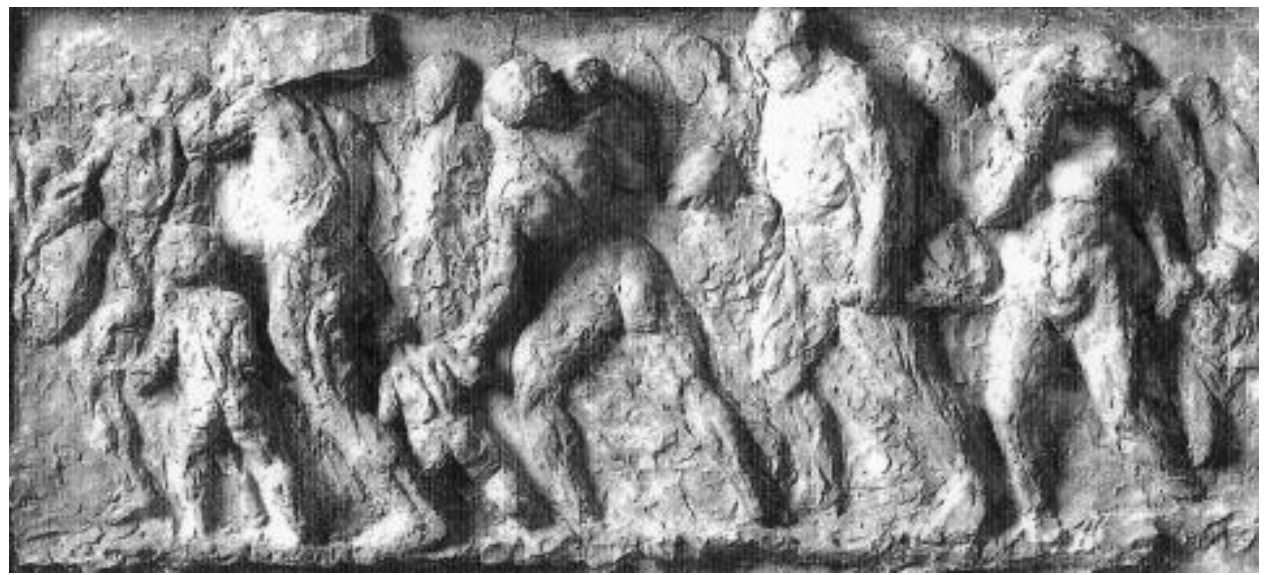

Figure 1. Les emigrants, Paris, Musée d'Orsay, Honoré Daumier, Catalog of the exhibition at the Grand Palais (5 octobre 1999 - 3 janvier 2000), Paris, RMN, 1999

Cultural participation is an essential dimension of the European statistical framework for culture (Eurostat, 2016). UNESCO emphasizes that cultural heritage is a world heritage in the hands of young people, which helps to promote discussion and listening to others with the consequent reaffirmation of identity and to foster mutual respect and respect for diversity. It also highlights how heritage can become a valuable bridge to bring together young people, teachers, heritage specialists and other interested parties in a social and cultural situation where they can learn from each other. This translates into knowledge and appreciation for their local and world heritage, as is clear in the World Heritage Education Programme initiated as a UNESCO special project in 1994, which gave young people a chance to voice their concerns and to become involved in the protection of our common cultural and natural heritage. It is also recalled that with the European Year of Cultural Heritage 2018 the goal has been to involving young people for an inclusive and sustainable Europe. In this context UNESCO and European Commission launched a pilot project that brings intangible cultural heritage closer to school communities throughout the European Union, with the aim of allowing children and young people to learn through and with heritage, encouraging them and stimulating them to explore their cultural heritage and actively participate in its safeguarding and transmission.

It's about feeding a culture capable of "building bridges instead of walls" and developing a "dynamic" multi-perspective approach of heritage (Grever \& van Boxtel, 2014), paying attention to ensure that cultural heritage and education are linked by a constant mutually positive relationship. In this regard for ICOMOS states that the concept of cultural heritage must be considered as a cornerstone of any cultural policy, constantly evolving. Suffice it to say The European Cultural Heritage Strategy for the 21st century further referred to as Strategy 21, who has focused on the three main components of cultural heritage: social, economic and territorial, and knowledge and education. 
An unparalleled series of initiatives and events have already been organized and will be organized in the future across Europe to get people closer to and more involved with their cultural heritage, to encourage the sharing and appreciation of Europe's rich heritage and to reinforce a sense of belonging to a common European space. Cultural heritage enriches the lives of citizens and helps to build a more cohesive society, but it is also economically stronger, providing employment and tourism opportunities.

The European Union has an important role to play working with Member States to safeguard and enhance Europe's cultural heritage and implements a range of policies realizing actions dedicated to cultural heritage

The EU survey on cultural heritage, Special Eurobarometer 466 (European Commission, 2017c), on value that the peoples attach to Europe's cultural heritage shows how the participation in cultural activities varies widely across countries, even if the lack of time remains the most common barrier to access cultural heritage (Fontal \& Cepeda, 2016; European Commission, 2017a; 2017b), sites or activities (37\%), followed by cost (34\%), a lack of interest (31\%) or a lack of information $(25 \%)$.

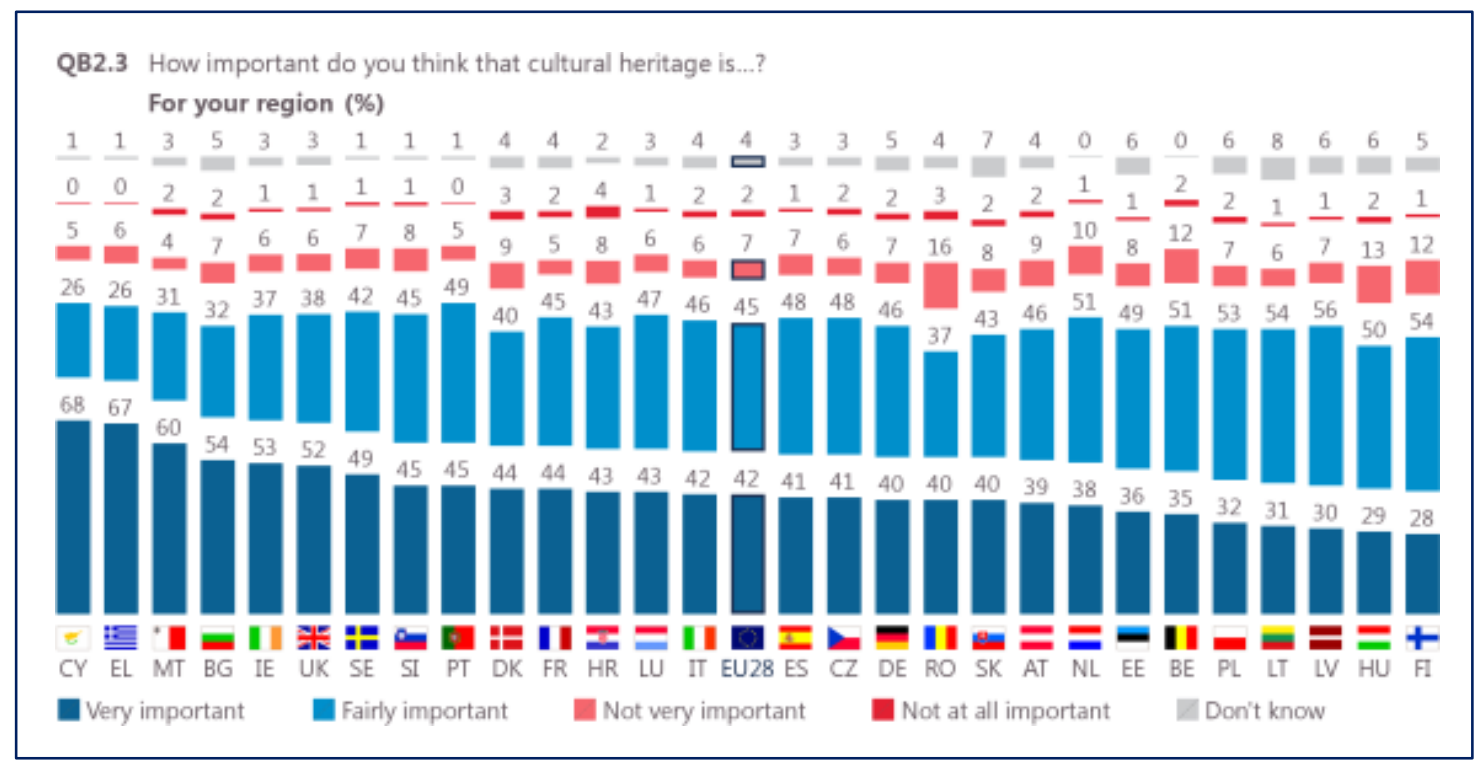

Base: all respondents $(N=27,881)$

Figure 2. Special Eurobarometer 466 (European Commission, 2017c)

It is observed how in all but one EU Member State, more than eight in ten respondents think cultural heritage is important for their country. Almost all respondents and think this way, and, among these, also Italy (87\%), together with Greece (97\%), Cyprus, Portugal, the Netherlands and Sweden (all 96\%), Romania (78\%), Hungary (86\%) and Belgium $(87 \%)$.

This brought out the trend towards a new "social rhythm" (Di Nallo \& Fabris, 2004), where the experiential practices of consumption and their ways of marking the time of the contemporary world determine the terms of a new cultural confrontation. It is useful, in this regard, to remember how the time of the experience of cultural fruition has gone, especially in recent years, gradually qualifying itself not only as a moment of "distraction" but also as an opportunity for the user to experience their cognitive pleasure and affective and to affirm their identity recognition, engaging it in a direct relationship to build the relationship between individual and group and to build the "feeling of belonging" to a certain community.

\section{When Heritage Education Becomes Culture}

Didactics and cultural mediation were born, the first, around the Sixties and, the second, between the Eighties and Ninetiest, to better fulfill the social responsibility of producing greater awareness about the importance of heritage for the community in terms of elaborating precise individual and collective conduct. This means to bring out the impact of the asset as a tool to increase a greater understanding of the cultural values involved and the traits that best identify the cultural heritage of a certain community, which reveal significant changes in the characteristics of the reference populations. Didactics and cultural mediation have linked to two emerging concepts: that of "democratization" and that 
of "schooling" (in the sense of cultural planning). Heritage appears to be a path that education and education can take to effectively combat cultural exclusion and to encourage the exchange of knowledge and skills, both inside and outside the education system, through the acquisition of languages, codes, structures, etc., which are the means to access the symbolic repertoires of culture, conceived as an expression of a humanity without classes and without borders. In this sense, the cultural asset appears to be one of the means capable of repairing the social divide created in the use since it encourages interdisciplinary research on the heritage of communities (Nuzzaci, 2016), on the environment and on their interrelationships, taking on three main functions:

- to oppose the fragility of social ties;

- to re-establish the sense of belonging of a community;

- to encourage the learning of new cultural forms.

In a society that critically questions itself, teaching and mediation are then presented as "devices" aimed at understanding culture and creating a social relationship built with the participation of the actors in a shared meaning. In particular, the teaching of cultural heritage, after a first moment of consistent problematicism linked to the articulation of its character and the not always clear link with the pedagogical literature, it has been declined in numerous domains (the teaching of artistic, demo-ethno-anthropological heritage etc.), assuming a complexity of ends and dimensions specific to the disciplines to which it refers, each of which has its own epistemological statutes, contents, forms of reasoning, methods, tools, languages and codes that lead to specific types of goods.

Progressively, in the field of heritage, teaching has tried to replace the "undifferentiated apologia" of artistic creation which has sacralized art and transformed the museum into a temple - with an idea of culture as a domain accessible to everyone, everyone and for all, who opposed the ancient concept of "feeling", "suggestion", "emotion" that of "learning", "achieving", "consolidating", bringing with it the value of acquisition as a process continuous experiential that involves all individuals at any age, opposing "understanding" to "common sense", which is as dense with "evocations" as it is restricted to the needs of those who are less favored.

If, therefore, it is necessary to schematically explain the teaching of heritage as the result of the attempt to specify culture and make it concretely usable by the various categories of public, it is equally true that it cannot be considered the last stage of the process of democratization of the asset, fulfillment of the cultural action of the 60s and animation of the 70s. Nor much less can be considered an active form of communication typical of the $80 \mathrm{~s}$, which served to renew the ways of intervention of cultural institutions; but it must be instead understood as a precise cultural method involving specific techniques for the detection of problems of understanding of the good by the community, adequate training courses that incorporate rigorously identified strategies and methodologies, defined cross-curricular approaches, well-defined inter-institutional partnerships that employ a wider range of communication methods. In its intrinsic ability to be able to enhance the potential of cultural heritage, wisely used as "a resource for sustainable development and the quality of life in a constantly evolving society", the teaching of the good is connected to the education process as a dimension apt to provide new cognitive answers and to increase the understanding of peculiar aspects of reality. Also facilitating the insertion of the dimension of cultural heritage at all levels of education, not necessarily in itself as an object of study, but as a fertile one source of studies and for other subjects, thus it helps to encourage interdisciplinarity, the transfer of competence etc., but above all an educational design that makes heritage the protagonist of cultural and social life. The teachers and heritage educators that continue practising culture and heritage education are doing practices of cultural rights that are key factors towards tolerance, civic and social integration. The different studies witness this implicit recognition and all recommend to have cultural heritage matters integrated in the local, regional and national education policies together with cultural and heritage policies (Gesche-Koning, 2018). Some examples of research, in this sense, have been elaborated in order to understand how to use heritage and its resources and to encourage alphabetic processes. Let's take two Italian examples like the (DIDarcheoMUS" Project and "Museum in...Click!" Project $(2015 ; 2017)$, focused on partnerships active in the University, school territory, which they predicted for inter-institutional collaboration between universities, schools, and territories conducted by the degree course in Primary Education Sciences of the University of L'Aquila. The project focused on the role assumed by technologies and cultural heritage within experience of active partnership aimed at strengthening the cultural and professional profile of future teachers (and those in service), through curricular and extracurricular experiences. By combining appropriate archaeological cultural assets of the territory and specific technologies, it has made it possible to renew precise methodological approaches of the "teaching science", in order to carry out increasingly effective teaching-learning processes and to provide increasingly updated sets of skills and knowledge with significant effects in terms of learning in the students. The same idea of systematization of educational activities that saw the Observatory Initiative on Heritage Education managed by the University of L'Aquila together with the Italia Nostra Association. This initiative concerned monitoring on the educational activities in the local and national territory and supporting general 
coordination for heritage training. Then we remember even Heritage Interpretation Project (2017), which envisaged the construction of integrated mediation professional profiles.

Therefore, it is necessary to give meaning to a new concept of heritage education not by limiting the latter to what appears useful in the contingency, but by qualifying it in the perspective of a life path - in the meaning of lifelong learning - that lasts over time and that is able to provide individuals the essential tools to correctly interpret cultural changes. This form of education, for the characteristics that are specific to it, is therefore conceived as capable of affecting the quality of the cognitive experience of the subjects by introducing them, through objects, into a present and past reality that would otherwise be inaccessible for them. The "good" combines the logic of the medium (communicative support) with cultural logic, and therefore symbolic, but cannot be considered only a channel, a physical support, a material substance that carries the meaning with it and transmits it. It is something that must be examined in the network of meanings and conventions that guide the recipient's perceptive attention. The "good" meaning, therefore, is not always immediately present without a work of correct decoding and appropriate mediation.

In the relationship of the object with the concrete recipient, you play the ability of teaching to intervene, with its purpose of mediation, pertinently on the learning sphere and to prevent the removal of symbols from the cultural profiles of the users, is played. This is because didactic communication differs from other forms of communication in that it presents selected signs and previously defined objectives, information emerges as an order of the elements of a system, and it is a form of communication oriented to produce learning.

From what has been said, it can be deduced that the significance of the goods does not exist in itself, but only in relation to lines based on the effective knowledge of everything that has accumulated around the phenomena of cultural communication and, above all, in relation to the main teaching functions that they are: stimulating affective states connected to learning; communicate the message; consolidate and apply the knowledge acquired; differentiate the learning proposal; implement learning assessment processes; and finally, activate appropriate checks on the adequacy of the procedures adopted (Nuzzaci, 2012).

Focusing, therefore, on the phenomenon of teaching in this sector mainly means putting the emphasis on the subject-object relationship, on the articulation of the statement rather than on the content, favouring reception rather than dissemination, and finally on learning that is also fun. At the same time, however, sometimes it has been exploited to the point of turning too frequently to the sphere of the elitist world, thus representing, once again, an educational experience for the few and restoring a "restricted" consumption logic. If at present, as a discipline and as a practice, it is characterized as a function of the passage between the object / its space of diffusion and its public cannot be interpreted reductive as a way of access to the object, but must enroll in the within specific cultural practices and public policies capable of modifying the role that the good plays in the formation of individuals, regardless of their social and cultural origin. In many cases, however, even today, cultural fruition continues to be an expression of certain social strata, so much so that it is taken internationally as a significant indicator of the state and cultural profiles of populations, that is to say, it is chosen as an index of segregation and / or cultural distinction, as well as precise normative scales of values. And this also explains why it is desirable that heritage training interventions should be integrated into school policies, capable of fueling the sense of responsibility and increasing the process of "awareness" of individuals for their cultural environment. While is clear that democratization processes continue to develop today in social fields where cultural heritage is experienced as a market and valued according to purely quantitative diffusion logics. The other aspect of this assimilation is that of blindness that Italian cultural policies demonstrate towards the usability of the good; firstly, because they often reduce its judgment of the taste on it, secondly, because they tend to further reinforce the illusion of a universal dimension in the exercise of taste. On the contrary, however, taste cannot be the main element of analysis of the evolution of the good-user relationship since it is a negative basic category, a "social sense of place", which, as Pierre Bourdieu (2001) states, reveals and assigns us a place in society, since, being a sort of social orientation, it guides the occupants of a given space towards social positions appropriate to their characteristics and practices; therefore it classifies and classifies what it classifies, in such a way that the different ways of acquisition generate differences on the very nature of preferences (Bourdieu, 2001), which are defined within a shared system of symbols, by means of which social interactions come into play and the individuals adapt to their environment, even in the presence of proposals made in technologically advanced environments and contexts (Panciroli \& Luigini, 2018).

Bourdieu, in agreement with other scholars such as Simmel (1997, pp. 187-206) or Veblen (1992), considers taste an invention of the upper classes who developed it in order to activate forms of differentiation in terms of social identity and cultural capital compared to the lower classes. For all the cultural activities the participation is often very rare for people with low educational attainment. Among all variables used for the analysis of cultural participation (age, sex etc.), the educational attainment is the one for which discrepancies across categories are the most visible. It is also observed a higher propensity to take part in cultural activities among people with higher levels of educational attainment (Eurostat, 2019, p. 134). 


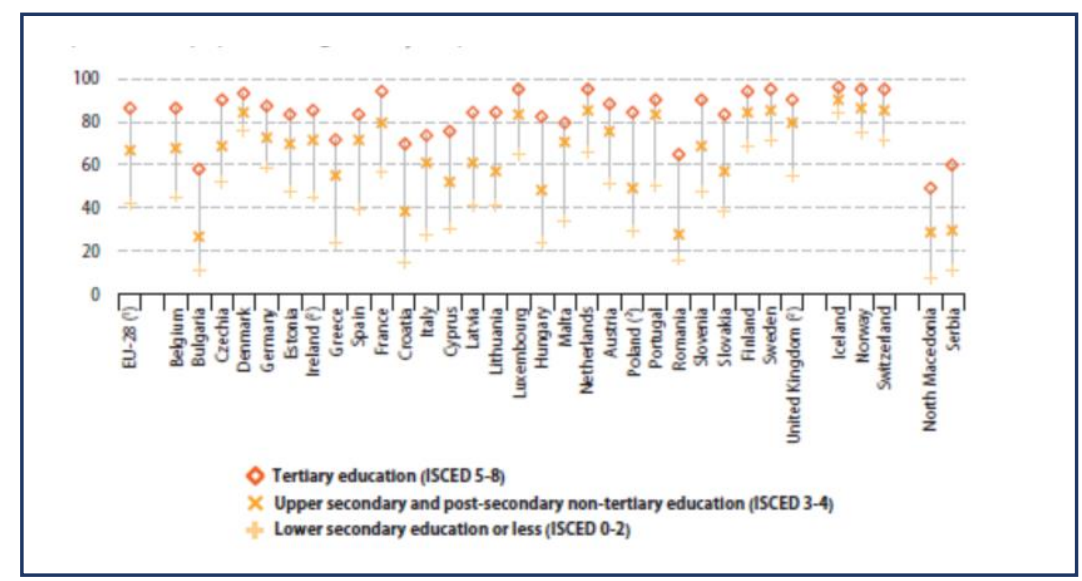

Figure 3. Cultural participation during the previous 12 months, by level of educational attainment, 2015 (\%, share of population aged $\geq 16$ years)

Conceived as an acquired disposition, aimed at "distinction", taste therefore qualifies as a culturally sophisticated way of making use of heritage, used by those who have learned to appreciate values, codes, basic rules, genres etc. of heritage, which feeds on a symbolic violence, exercised by the dominant layers on the dominated layers, which provides for the imposition of precise visions of the world, social roles, cognitive categories, structures mental through which the world is perceived and thought; these are categories that reproduce the patterns of domination within a space that confers legitimacy in the form of symbolic capital. Here it is interesting to recall the other central concept in Bourdieu's theories, that of "habitus", which he defines as a system of acquiring operating arrangements at a practical level and of categories of perception and classificatory evaluation that organize the principles of action (Bourdieu, 1972, pp. 1105-1127; Bourdieu, 1969: 1972; Bourdieu \& Passeron, 1970), which allows to explain the way in which a social being internalizes the dominant culture (the doxa) by reproducing it.

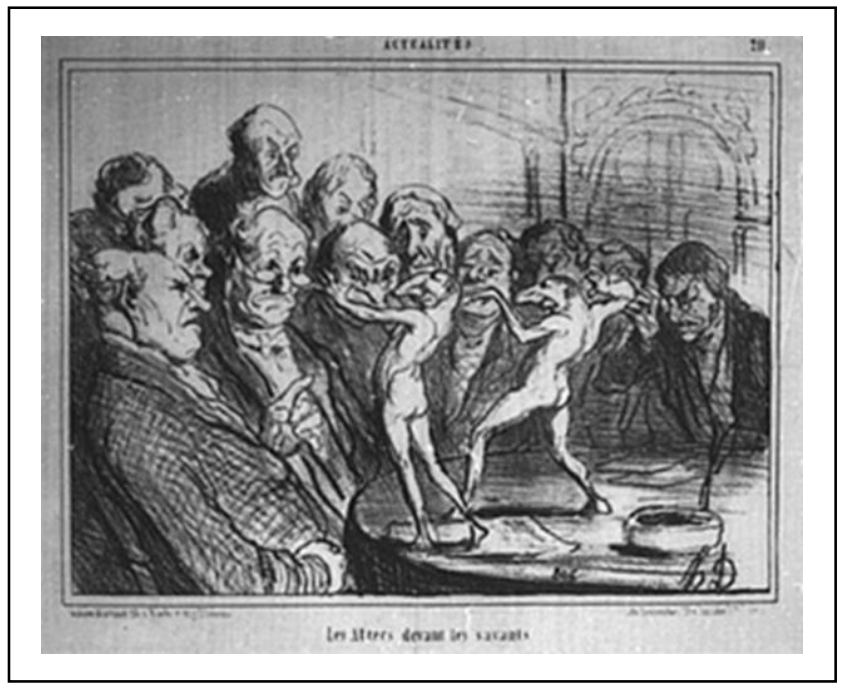

Figure 4. Les Aztèques devant les scientifiques, lithography, plaque 211 from Actualités, 1855, Honoré Daumier

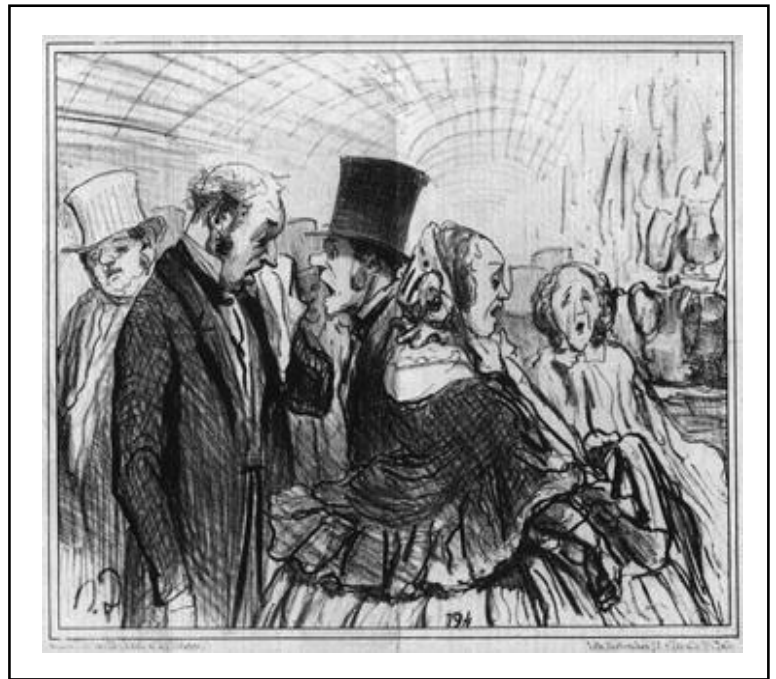

Figure 5. La peintre qui a eu un tableau refuse, lithography, from L'Exposition de 1859, published in Le Charivari, April 27, 1859, Honoré Daumier 


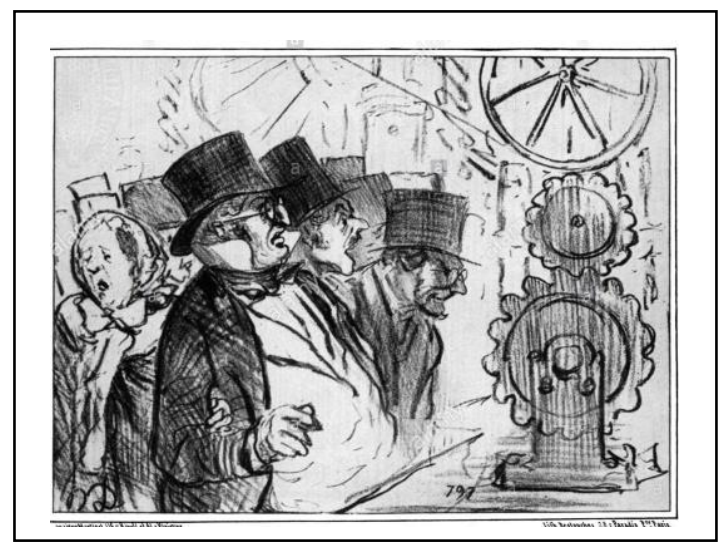

Figure 6. Exhibitions, world exhibition, Paris, caricature, turnspit, drawing by Honore Daumier, 1867, 19th Century, Universelle exhibition

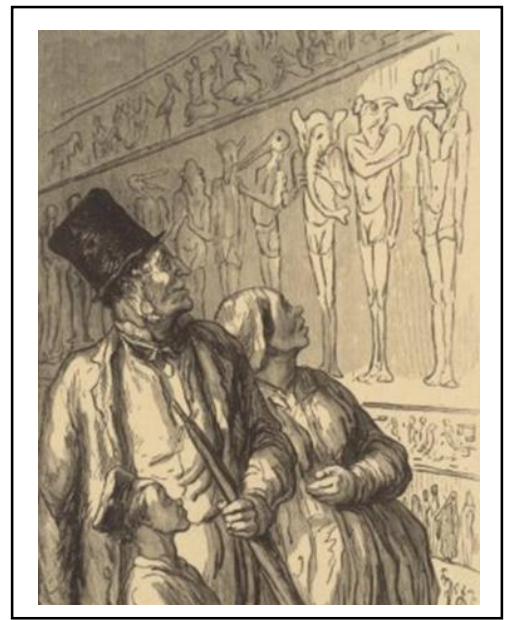

Figure 6. A l'Exposition Universelle Section Égyptienne, 1867, Honoré Daumier, reprinted 1920

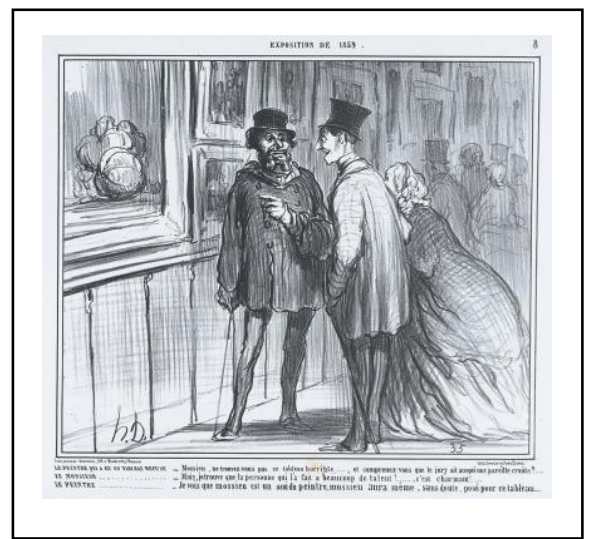

Figure 7. La peintre qui a eu un tableau refuse, from L'Exposition of 1859, Honoré Daumier, published in Le Charivari, April 27, 1859

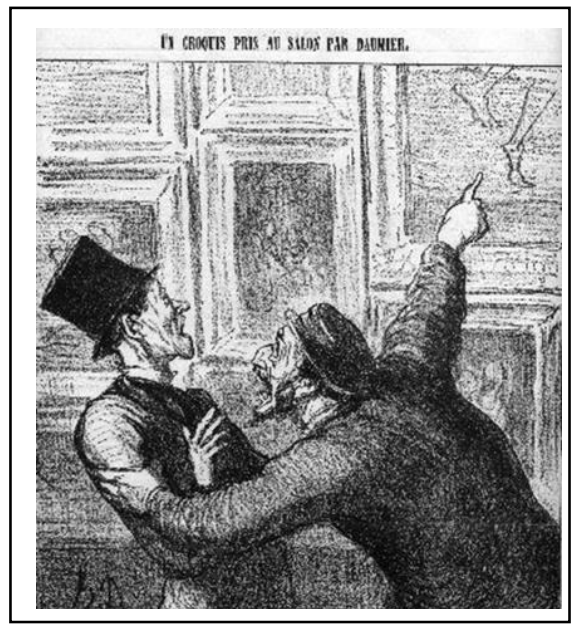

Figure 7., A l'Exposition Universelle Section Ëgyptienne, 1867, Honoré Daumier, reprinted 1920

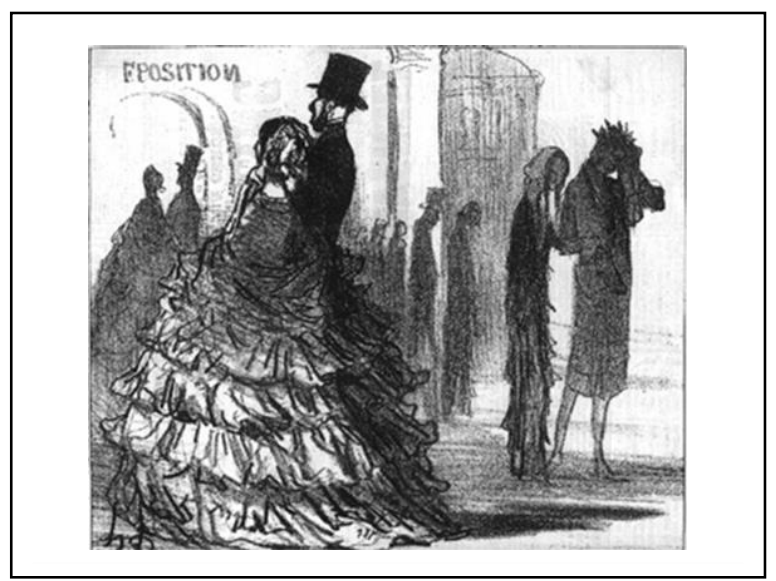

Figure 8. Comment on entrera à l'Exposition Universelle, 1855, Honoré Daumier

A fundamental element of cultural reproduction, the "habitus" is what regulates the interactions of a group or class within an observable field and which Sulkunen (1982) defines as a symbolic order within which it carries out its 
practices (p. 1088). In this way, for which reality is built, the symbolic processes are maintained and transformed allowing the sharing of sensitive and intelligible experience. This is because social knowledge is not given independently of the languages and symbolic forms. What has been said so far leads us to consider teaching as an "artificial" domain that allows learning and the consolidation of experience, mechanisms without which the good would return to oblivion. In this sense, goods are to be understood as "signs" that can leave a trace in our experience if, "culturally impressing" our senses, they sediment the different acquisitions by imprinting them in our interpretative repertoire. Being able to interpret these signs, as Ricoeur (1986, p. 839) says well, "means understanding man" through an analysis of the fundamental constituents of culture.

It seems appropriate, in this regard, to recall the notion of "symbolic form" proposed by Ernst Cassirer (1988), who recognizes the configuration and articulation of symbolic forms in what he calls "the general function of symbolization" by referring it to all the activities of the "Spirit", with particular regard to those that materialize in cultural and artistic productions. He argues that symbolic forms organize man's perception of the surrounding world and his experience, substantiating the matter of lived knowledge. More briefly, we can say that, in his opinion, the acquisition of the symbol constitutes an indispensable step for the assumption of objective knowledge and for the formation of the relationship between subjective and objective being. This idea, which is then reused by Erwin Panofsky (1999) in the domain of painting, immediately shows, taking as an example the perspective, the profile / cultural capital-symbol-good relationship. The semiologist explains, starting from the concept of semiophore asset (bearer of signs) that he developed in the context of the philosophy of symbolic goods, how perspective is to be understood as something more than a style that declines in different forms according to the ages, that is, conceived as a product, it actually offers both a conceptual and representative model, revealing itself as an interpretative framework of representation that oversees the vision of reality.

This is a conception that applies to both the cultural and scientific domain and which highlights the role assumed by the user, as a subject that represents an object starting from a particular point of view, in the process of perception and construction of reality. It is a novelty that seriously undermines a generally accepted, even if implicit, criterion of fruition as an "overabundant quantity of volatile acquisitions", emphasizing instead the role that cultural heritage could play in the educational processes of children, teenagers and adults, in order to increase the repertoires of basic skills and to stabilize them, updating them, according to the gradually emerging needs. It follows the need to review the criteria on which the education of cultural heritage is based within the school, but also to implement a systematic action that develops outside education, with the aim of preserving as fully as possible the "desire for culture".

Cultural heritage is worldwide and culture is not owned by people, classes, individual countries but belongs to everyone, he wrote in an article entitled "Beni culturali, ma di chi?" of 1986 Giulio Carlo Argan, who stood up in defense of that heritage which he saw increasingly threatened by the interests of private individuals and by the demolition of the state, that is, according to him, the civil conscience of citizens. Argan's speech immediately introduces us to the heart of our speech which sees knowledge and respect for cultural and natural heritage with a view to citizenship and identity education.

\section{Didactics as a Mediation Process}

Traditionally, reflections on education in cultural heritage have mainly focused on the production level, that it is to say on the economy of spectacular forms of good, or according to the needs of certain categories of public. However, it is my intention to follow another perspective: that of receiving and understanding the messages of which the good is the bearer and the ability of teaching to make them explicit and accessible every individual. When we talk about reception, we refer to those conditions for which the individual comes into contact with the object by activating a process of understanding the good by which a message is made by a "recipient" or "recipient". This contact directs the effects of appropriation or rejection, of distraction or attention, of emotion and / or reflection, of involvement or of distance that the object arouses towards the subject. These differentiated attitudes of reception do not depend solely on the structure and shape of the object or process, but also on the behaviors (cognitive, affective, social, etc.) implemented by the recipient.

Reception is therefore structured also in relation to the expectations of the public, conditioned by norms, habits, socio-cultural variables and so on. It is however clear that, from the point of view of semiotics, the act of reception itself can be said to be a fundamental element of the communicative process, which in its complexity brings into play the actions, behaviors and attitudes of the recipient in a "horizon of meaning" that is given by the set of possibilities not yet experienced that through it enter the sphere of different and personal ways in which the experience of fruition flows, thus determining new learning. In this perspective, then, the "waiting horizon" of the user is fixed in an objectively formulated reference system resulting from three main factors: previous experience in terms of use, knowledge about the forms and types of goods, the favourable disposition in terms of fruitful will. 
These three components guide the experience of the user with the good and configure it as an activity that diversifies in relation to the occasions of use and the quality of the encounters with the heritage. From here we understand how cultural practices make sense in a complex organism made up of attitudes, behaviors etc. that shape the perception of heritage, whose accessibility is not determined only by the conditions of the offer, that is to say by the extension of the domain of the circulation of objects to potential audiences, but by a greater synergy between the competences of the subject and those of the actors institutional stakeholders. Similar recommendations aimed at highlighting the importance of building synergies between education and culture been also processed by the Culture Action Europe Association for adult education and the European Commission (2017) in the Communication on "Strengthening European Identity through Education and Culture".

It follows, however, that individuals, although facing an ever wider range of fields of knowledge, do not always succeed in taking advantage of the relationship with the good, because the greater extension of the opportunities for use does not always correspond to an effective variety and quality of learning experiences, in terms of qualitative reception and actual internalization of acquisitions.

In order for a level of knowledge to be associated with fruition, it is necessary to be able to count on specific areas of competence and to have selective cultural proposals that can create better learning conditions and make the conservation of skills more solid. These are the most important prerequisites for being able to consciously enjoy cultural heritage throughout one's life and for giving meaning to citizens' participation in democratic society.

If it is true that fairer societies produce more accessible and easily shareable cultures (Shaeffer, 2000, p. 41), it is equally true that what has been said is attributable to cultural democratization, which is defined within a certain area, by inscribing the latter in a specific space and history that they must be examined with reference to social stratifications. The exercise of the right to the use of cultural heritage, especially by young and disadvantaged people, serves to increase awareness of the value of culture and to maintain and preserve the benefits that can be drawn from it in a democratic society that protects the public interest, rights and freedom. If it is certain that the extension of the audience of users has led to more qualified public cultural policies related to certain types of goods and users, however this has not always been enough to change the criteria for appreciating the heritage and the elements of its democratization, which often ended up being based almost exclusively on a strategy of generalization of access to the consumption of the cultural product.

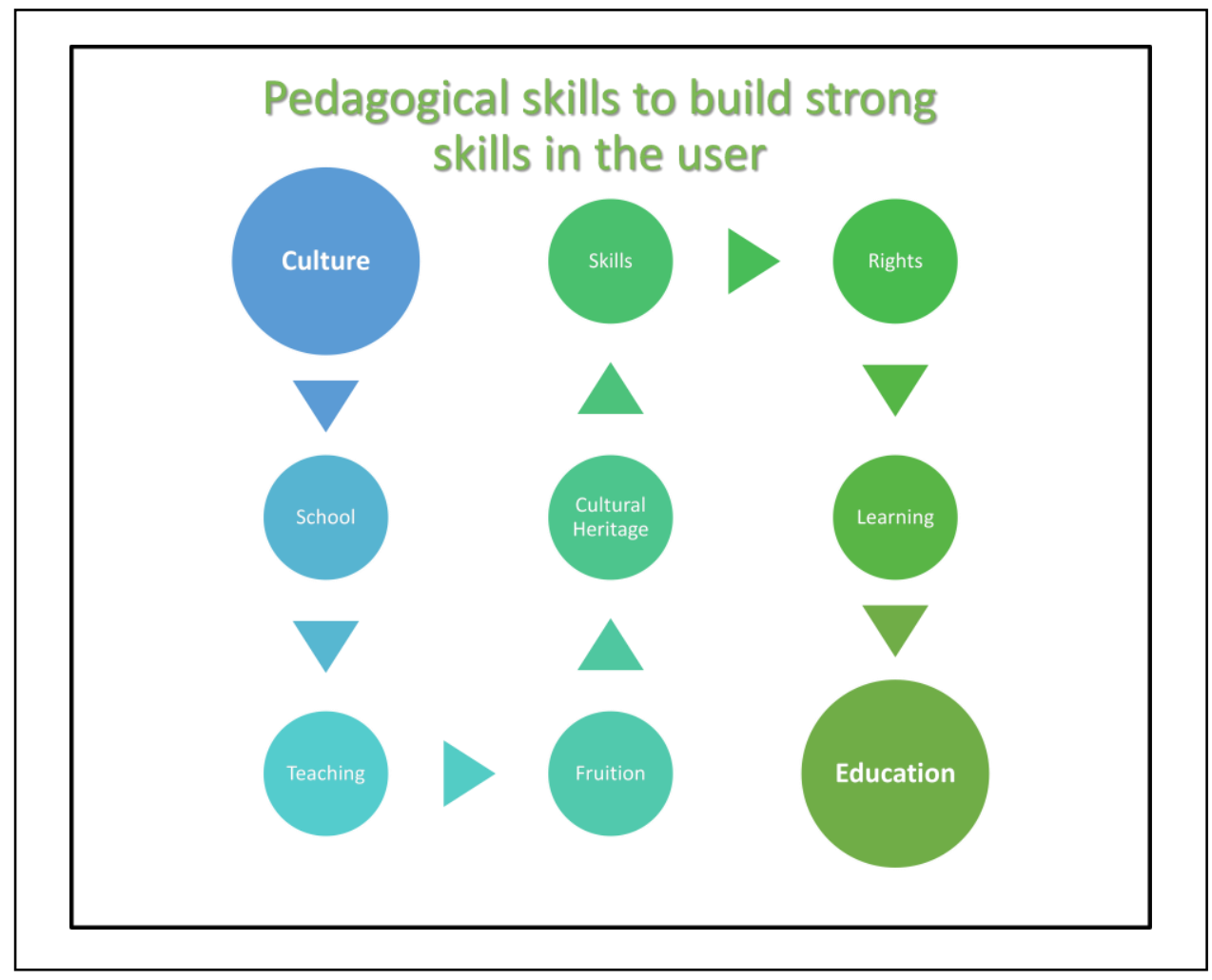

Figure 9. Cultural participation, Education, Rights, Antonella Nuzzaci 
Now it remains to be seen whether the current processes and criteria for assessing the policies of the institutions, which have gradually become impregnated with a quantitative dimension of the enjoyment and appreciation of media legitimization circles, actually facilitate access by a mass always wider range of individuals with cultural resources that favor the acquisition of symbolic systems.

Frequently, the return on investments has almost always been assessed in the short term without taking into account the qualitative effects on the development of individual learning and on the growth of mediation characteristics. In this context, it is clear how public action has become extremely relevant for the community, strengthening above all with the expansion of schooling and with the intervention of education aimed at ensuring the exercise of the right to literacy, factors that have acted positively on the process of cultural democratization, developing a new concept of culture and good. Schooling and cultural democratization can therefore be said to be two sides of the same coin. We find, in fact, associated with education to cultural heritage the construction of profiles of the population, which sees, in the enlargement of the public, in taking into account cultural inequalities, in the discovery of new actors, in raising awareness of fruitful practices, the emergence of new stimuli capable of increasing innovative forms of cultural action.

Then, in order to follow a path of progress, education is required to outline more certain profiles and propose training interventions distributed throughout life. For example, intervening on adults, with proposals that specifically qualify for their educational character, can have an accelerating effect in achieving new cultural objectives and increasing the positive relationship between the experience that children and young people have in school and the one that it is proposed to adult generations. This would lead to feeding that pool of skills through which it is possible to learn the good at all ages and to complete the process of democratic fruition. In the past, the fact that heritage has long been largely ignored by education has made the role of cultural heritage marginal in the growth of repertoires. For this reason, it is appropriate to move towards educational mediation starting from the analysis of a broad dimension such as that of the study of the cultural practices of the various audiences and without which the discourses on democratization remain only a vain theory. Also because heritage does not have an educational function in itself but must place itself at the service of training, while in its classical conception it has always been subjected to other forms of cultural experience and instrumentally, as well as generically, used to face philosophical issues, to illustrate knowledge literary and scientific and so on. Furthermore, it was interpreted solely from the point of view of the emotional impact that the user derived from it by producing a type of reflection focused mainly on aspects concerning the "pleasure" induced by the perceptive contact with it.

At the basis of the "emotional reaction", determined following the relationship between subject and object, was the "suggestion", which, negative or positive, could, if properly stimulated (by the structure, the suspense, the surprise, etc.), keep alive the attention of the user and involve him in the hope of being able to affect, in some way, his beliefs, his thoughts, the conditions, his motivations without ever making him participate in the change and learning. The visitor's experience of use was conceived as a progressive process of "emotional immersion" in an atmosphere in which objects seemed to float in the void, perceptually free of sharp boundaries, but poorly "redesigned" by the visitor's gaze. Contrary to popular belief, we know, in fact, that one cannot hope to enjoy something if one does not fully understand it, since objects acquire meaning and value only for those individuals who are able to decode and appreciate them; and this is a general principle recognized and fairly shared in education. For this reason, talking about terms such as "learning" and "teaching" in this field should not be frightening, but their use must be re-contextualized and re-centered as it refers to processes and interventions that help make the experience "meaningful" for he who does it; these are terms which, while referring to the formal education system, are capable of calling into question both the definition of heritage and its methods of transmission and construction, introducing that dose of problematicism that is the very soul of culture, of renewal and science.

Heritage can therefore be said to be a complex phenomenon, not so much for the breadth of knowledge it implies, but for the work on the representations it requires to change the look on man, on knowledge, on childhood, on reality and on himself same. For its intrinsic qualities and for the powerful learning function it performs, it can succeed in counteracting the eradication of a culture of subordination which presents stronger suggestions than that which should guarantee each one a certain autonomy of thought.

\section{The "Goods" as Culture and as Language: User Skills and Conscious Use of Heritage}

Cultural goods make a qualitative leap when they become cultural forms also considered from a linguistic point of view. We recall what was stated by Roman Jacobson (1963) which identifies the presence of two axes in language: that of selection (the choice of words from a series of words existing in the language) and that of the combination of the linguistic units of the utterance (the message) that makes sense. Cultural heritage fully realizes these two ways used in linguistic communication. These are languages in the strict sense of the term, insofar as the choice of vocabulary (selection) and syntax (combination) come from two operations which are the selection of the material taken from 
reality and its composition in an artistic, archaeological logic, anthropological etc.

Just as a way of intervening on the real and the imaginary, they can thus be considered real symbolic forms, by reason of which the individual acquires the foundations of a common culture. It is the intentionality of fruition, that is, the property of identifying and understanding the meanings that the good generates, and that the teaching calls for, to allow the different types of cultural production to be analyzed from the point of view of their effects on learning. With reference to the expressive plurality of the good (plastic, visual etc.) and the intentionality of the lived experience, in fact, we are led to trace three central characteristics in the process of appropriation of the good and its relationship with the other spheres of culture. First of all, we can say that goods not only provide informative data, but participate and act within an ordered cultural universe relevant from the point of view of the communication process, not only for the information they transmit but above all for the relationships they establish. Secondly, they are at the base of the process of existence, elaboration and permanence of a community and can be said of the symbolic structures through which reality is built maintained and transformed allowing subjects to share cultural experience.

It is in this passage of sedimentation and renewal of cultural processes and fruitful behavior patterns that culture, as a set of symbolic relationships that forge the feeling of belonging of a community within its precise history and "destiny", has rarely been the object an accurate didactic reflection about the levels and domains of competence required to fulfill a quality fruition meeting the needs of different types of users (and requiring public intervention). In this regard it is useful to remember that knowledge of the social world is not given independently of these languages and these symbolic forms, as their learning accompanies and conditions the consciousness of the individual (and of the community) by inscribing the latter in society and in reference culture. We also keep in mind that the symbolic function does not unfold only in articulated languages, but also finds concretization in the organization, conceptualization and use of objects in the world. Therefore, it is with the knowledge and use of these languages that the symbol is interpreted, which reveals its latent sense and establishes a deep and two-way relationship between what it means immediately and what it refers to.

From here it is clear how cultural goods, conceived as languages, contribute to making us understand better the sense of learning itself, widening the boundaries of the production of knowledge. However, without understanding the structural systems, the codes with which goods are connoted, there is no possibility of decoding the "signs" of culture, which in turn recall acquisitions from specific fields of knowledge (physics, mathematics, history etc.) and whose characters appear to be linked to the modification of a quantity of components. In other words, the understanding of the cultural asset, if it does not pass through the deciphering of the structural elements of the object, risks focusing on interventions capable of acting only temporarily on the profiles, without producing stable advantages for learning.

Indeed, numerous other factors, cognitive, affective, of social origin, as well as the vision of reality, the universe of knowledge and the known codes, affect the quality of reception and the persistence of learning. Consequently, what has been said immediately introduces the problem of the user skills that are necessary to successfully access the complex and multiple reading plans of the property. The hypothetically "competent" user is the one who is "adequate" to the message, that is, defined by the ability to receive the information proposed to him. In reality, although the information can be unequally and differently deciphered by different subjects, the fact remains that the attendance with the good and the custom to use it are two components that lead towards the mastery of the message code and the adhesion to a system. of values that determines the reading of the information allowing its appreciation.

An in-depth analysis of this type is therefore linked to a theory of the teaching of cultural heritage variously divided between "user skills" and "sector teaching skills", necessarily providing for an interdisciplinary approach to the problem of cultural enjoyment. Only an integrated approach to heritage guarantee that the multiple benefits of cultural heritage are realised in practice, as stated in the Cultural Heritage counts for Europe report (Europa Nostra, 2015). In this discourse there are two interconnected conceptions. The first concerns the need to equip yourself with an instrumental apparatus, declined in specific skills and abilities, to understand the languages with which cultural heritage is "written" and to promote creativity, flexibility, adaptability, the competence of "learning to learn "and to solve" problems "(transversal skills), thus underlining how important and broad basic training is important in the interpretation of heritage; according to this conception, the asset is conceived as an instrument capable of increasing the cognitive and social skills possessed by the individual.

The second part is based on the idea that cultural heritage didactics experts must possess specialist skills (disciplinary, methodological, didactic etc.) that enable them to carry out an examination of the problems of receiving and functioning of the proposed message, in such a way to guarantee to all users the understanding of the information issued through the formulation of suitable cultural proposals. In this reasoning, the "issuer" of the message and the "recipient" are united by the forms of communication adopted, both in their formal solutions and in their insertion in specific contexts. In any case, we can put forward the hypothesis that the use is placed on an asymmetry level, which historically characterizes the organization of mass communications, and which derives from "the different quality of the communication skills of 
issuers and receivers (know-how vs. knowing-recognizing) and the differentiated articulation (between issuers and receivers) of the criteria of relevance and significance of the texts" (Wolf, 1985, p. 128) that the "good", understood as "medium", produces. The main task of teaching cultural heritage is to try to fill this asymmetry.

As we have seen, it relates to the process of creating knowledge and is directly linked to the development of specific acquisitions in the context of heritage, especially the museum. We can say that the behaviors of the subjects, in particular of the young, towards the good, if adequately stimulated, follow their evolution that originates from a relationship of familiarity, knowledge and attendance with the good, following which they are progressively learned from the user the main components and functions of fruition: ways, contents, expressed meanings. All this requires a complex mediation work, conducted by the school in partnership with the other institutions, which implies an intense design work to make the use more selective, continuous and effective, that is, responsive to the real needs of individuals. This design, which can only be conceived as "integrated", arises from common basic choices on learning the cultural asset as a lasting dimension and is expressed concretely in the objectives, actions and educational proposals. It is a partnership between the institutions which provides for the construction of a "common territory" capable of giving coherence to the mediation proposals that are gradually offered at local level.

In the Council of Europe's Framework Convention on the Value of Cultural Heritage for Society, published in Faro on 27 October 2005, a framework is defined with regard to heritage and the importance of educational action is stressed as a factor of peace and conflict prevention through interpersonal and intercultural dialogue and mutual understanding. Cultural heritage is interpreted here as a "way of learning", access to which should be encouraged "in order to increase awareness of its value, the need to maintain and preserve and the benefits that can be derived from it". Conceived as a "trace of human activities", it calls for the development of heritage-based teaching strategies, which in itself incorporates unpublished active "methods" and cross-curricular productive approaches to the field of training at all levels of the teaching process-learning.

The Convention noting the importance of partnerships between the field of education and that of culture actually tries to recognize the variety of ways of communication and expression that can be used to improve both the professionalism of those who work in the field of education and training (teachers, educators, etc.) and those who work within organizations that deal with cultural heritage (heritage education experts). In essence, it is a matter of committing to the reconstruction of a cultural framework that looks at "heritage" as an element open to the new needs of training and the development of society, increasing the educational offer in this sense and proposing shared and stable partnerships between the school, the territory and other cultural institutions. The protagonist of the change, education must make sense of these new proposals by qualifying them in a long-term perspective, so as to concretely increase the conditions for access to culture.

The learning of goods is a terrain that clearly shows that there is a need first of all for solid basic skills, which are the prerequisites and the foundation for the subsequent autonomous learning of reading the good. Through the experience mediated by the didactic action, the subject appropriates a series of skills that implement a development process that can be started very early and that includes the perception, reading and interpretation of the good. But it should be remembered that the growth of the repertoires of competence supports the processes of "decoding" and does not assume a purely instrumental function, since it constitutes an extraordinary "pool of knowledge" that enriches linguistic, cognitive, affective heritages and feeds plural and the plurality of reflection.

The experience of fruition manages to support and be supported by the development of skills when, by entering the "continuum" of training, it is interrelated with other learning processes. This leads to the necessary distinction between different areas of competence that can allow the passage to a conscious fruition; among which we indicate, by way of example, only a few:

1. know the different codes (visual, etc.) and the different forms of cultural expression;

2. be able to decode the different languages;

3. possess digital skills;

4. learning to learn;

5. possess adequate interpersonal, intercultural, social and civic skills.

These skills are directly related to: the ability to recognize the building blocks of the languages of goods, closely related to basic and disciplinary and specialist learning (alphabetical skills in the mother tongue, in mathematics, science, technology etc.), the ability to identify the different forms of cultural expression, connected to the construction of identity processes and to the interpersonal, intercultural, social and civic dimensions that play an important role in promoting the construction of collective identity; to the possibility of interpreting and reinterpreting, of producing and reconstructing the processes of cultural acquisition that enable subjects to learn to learn throughout their lives. 
The experience of the asset is however a complex fact, which sees many different and interacting factors acting which influence the acquisition process, the preferences gained, the situation in which the experience takes place and the entry prerequisites. However, we cannot forget that it is first of all literacy that is, the ability to read and understand goods, as well as to perceive them in their different forms, differences and representations. This knowledge founds the learning sequences of the asset in a taxonomic sense and connects them within the curricular paths and training objectives.

There is now a large international literature that demonstrates how heritage able to influence many kinds of learning, behavior, conduct, perceptions etc. But it also highlighted the contamination and the effects produced by strengthening the relationship between school and cultural skills, suggesting the positive value produced as whole by this relationship. In fact, due to its structural aspects, the goods, in their plurality and immediacy, generate an intentional "listening" to the data of culture and its identity, in particular of the ways in which cultural preferences are built within the processes. identity, such as for example the understanding of cultural diversity, the multiplicity of languages etc.

However, it is above all educational research (Nuzzaci, 2012) that can do a lot to determine the impact that learning cultural heritage has on training and to study the educational phenomena related to this problem, helping to understand: how children learn to approach cultural heritage and what the optimal development levels can be to define the different skills and types of experience that should be carried out in this area; what strategies to use to facilitate individuals in the process of acquiring knowledge and skills useful for learning goods; what materials and techniques to use to motivate students to participate in the interpretation and re-interpretation of the "good"; what methodologies to use to support students in the application of acquired skills and knowledge and in the transfer of what has been learned to other situations, ie how to "reuse" what has been learned in the field of cultural heritage to solve problems of different kinds and vice versa; how to develop positive attitudes towards cultural heritage and towards less unknown experiences; how to identify learning sequences or teaching techniques that lead to an authentic understanding of the good in order to obtain adequate performance; what is important in the first experiences that children have with the good; if there are "key" learning or attitudes in education for understanding the good; how the willingness to use the good is built; what are the procedures and protocols (disciplinary and interdisciplinary) for the development and maintenance of a good heritage teaching; how to ensure continuity between learning experiences with the good carried out at school level and those that take place outside of school and so on. Understanding then how the use of goods enters into relationship with the nature of the new alphabetic forms, which revolve around the domain of "multiliteracies", today appears to be a central objective to favor understanding strategies that allow each individual to master the essential skills for the assumption and production of multiple learning modalities aimed at facing increasingly complex tasks and at identifying flexible solutions for knowledge orientation (Nuzzaci, 2011).

These questions constitute the "heart" of a teaching of the good that leads towards the path of learning and educational success and to which only educational research, in its relationship with the museum sciences, is able to provide a comprehensive answer. And this is because the research of science makes it possible to access solutions, which, although temporary, strongly guarantee the redesign of the future and the rethinking of the ways in which man's relationship with culture (local, national and international) is realized. Trying to understand culture therefore remains the most important condition of human existence.

\section{References}

Argan, G. C. (1986). Beni culturali, ma di chi? Insegnare, 2(7-8), 7-9.

Baldriga, I. (2020). Estetica della cittadinanza. Per una nuova educazione civica. Firenze: Le Monnier.

Bourdieu, P. (1972). Esquisse d'une théorie de la pratique. Genève: Droz. https://doi.org/10.3917/droz.bourd.1972.01

Bourdieu, P. (1972). Les stratégies matrimoniales dans le système de reproduction. Annales ESC, 27(4-5), 1105-1127. https://doi.org/10.3406/ahess.1972.422586

Bourdieu, P. (1979). La Distinction: critique sociale du jugement. Paris: Éditions de Minuit.

Bourdieu, P., \& Passeron, J. C. (1970). La reproduction. Éléments pour une théorie du système d'enseignement. Paris: Minuit.

Cassirer, E. (1988). Filosofia delle forme simboliche (1923). Firenze: La Nuova Italia.

Collard, P., \& Witte, R. (2015). Creative alliances for Europe. CCE and BKJ.

Di Nallo, E., \& Fabris, G. (Eds.) (2004). L'esperienza del tempo di consumo tra pratiche e fruizione sociale. Milano: FrancoAngeli.

Europa Nostra (2015). Cultural heritage counts for Europe. Towards a European index for valuing cultural heritage. Retrieved from https://issuu.com/europanostra/docs/chcfe_final_conference_e_reader

European Commission. (2017a). Mapping of cultural heritage actions in European Union policies, programmes and 
activities. Retrieved from http://ec.europa.eu/assets/eac/culture/library/reports/2014-heritage-mapping_en.pdf

European Commission. (2017b). Strengthening European identity through education and culture. Retrieved from https://ec.europa.eu/com/mission/sites/beta-political/files/communicationstrengthening-european-identity-educatio n-culture_en.pdf

European Commission (2017c). Special Eurobarometer 466 - October 2017. "Cultural Heritage" Report. Retrieved from http://ec.europa.eu/commfrontoffice/publicopinion

Eurostat. (2019). Culture statistics. Luxembourg: Publications Office of the European Union.

Fontal, O., \& Marin-Cepeda, S. (2016). Heritage education in museums: an inclusion-focused model. The International Journal of the Inclusive Museum, 9(4), 47-64. https://doi.org/10.18848/1835-2014/CGP/v09i04/47-64

Gesche-Koning, N. (2018). Research for CULT Committee. Education in Cultural Heritage. Brussels: European Parliament, Policy Department for Structural and Cohesion Policies.

Grever, M., \& Boxtel, C. van (2014). Erfgoed, onderwijs en historisch besef. Verlangen naar een tastbaar verleden. Hilversum: Uitgeverij Verloren.

Jakobson, R. (1963). Saggi di linguistica generale. Milano: Feltrinelli.

Nuzzaci, A. (2012). La ricerca empirica nell'educazione al patrimonio e nella didattica museale. Lecce-Brescia: Pensa MultiMedia Editore s.r.l.

Nuzzaci, A. (2015). University, School, Territory: strategies and activities of inter-institutional partnerships of the Degree Course in Sciences of Primary Education. In P. Blessinger \& B. Cozza, IHET. University Partnerships for Community and School System Development (Vol. 5, pp. 233-258 - Innovations in Higher Education Teaching and Learning). Bingley: Emerald Group Publishing. https://doi.org/10.1108/S2055-364120150000005013

Nuzzaci, A. (2016). I beni culturali tra competenze, identità e atteggiamento verso la fruizione: il ruolo della ricerca educativa. In T. Aja, L. Calandra, \& A. Vaccarelli (Eds.), L'educazione outdoor: territorio, cittadinanza, identità plurali fuori dalle aule scolastiche (pp. 178-193). Lecce-Brescia: Pensa MultiMedia Editore s.r.l.

Nuzzaci, A. (2017). ICT, beni culturali e formazione iniziale e in servizio degli insegnanti: il progetto "Il Museo in...Click!". In P. Limone \& D. Parmigiani (Eds.). 'L'educazione digitale' - Modelli pedagogici e pratiche didattiche per la formazione iniziale e in servizio degli insegnanti (pp. 258-271). SIREM 2016. Bari: Progedit.

Nuzzaci, A. (Ed.) (2011). Patrimoni culturali, educazioni, territori: verso un'idea di multiliteracy. Lecce-Brescia: Pensa MultiMedia Editore s.r.l.

Panciroli, C., \& Luigini, A. (Ed.) (2018). Ambienti digitali per l'educazione all'arte e al patrimonio. Milano: FrancoAngeli.

Panciroli, C., \& Macauda, A. (2017). The space as an educational and a didactic tool of interpretation: the example of the atelier of 'The child and the city'. Ricerche di Pedagogia e Didattica, 12(1), 131-140.

Panofsky, E. (1999). La prospettiva come forma simbolica (1927). Milano: Feltrinelli.

Ricoeur. (1986). Du texte à l'action. Essais d'herméneutique II. Paris: Seuil. https://doi.org/10.14375/NP.9782020093774

Shaeffer, J. M. (2000). Adieu à l'esthétique. Paris: PUF. https://doi.org/10.3917/puf.schae.2000.01

Simmel, G. (1997). The philosophy of fashion (1905). In D. Frisby \& M. Featherstone (Eds.), Simmel on culture (pp. 187-206). London: Sage.

Sulkunen, P. (1982). Society made visible-on the cultural sociology of Pierre Bourdieu. Acta Sociologica, 25(2), 103-115. https://doi.org/10.1177/000169938202500201

Veblen, T. (1992). The theory of the leisure class (1899). London: New MacMillan.

Wallace-Casey, C. (2017). "I like to take everything and put it in my own words": historical consciousness, historical thinking, and learning with community history museums. Canadian Journal of Education / Revue Canadienne de l'éducation, 40(1), 1-28.

Wolf, M. (1985). Teorie della comunicazione di massa. Milano: Bompiani.

\section{Copyrights}

Copyright for this article is retained by the author(s), with first publication rights granted to the journal.

This is an open-access article distributed under the terms and conditions of the Creative Commons Attribution license which permits unrestricted use, distribution, and reproduction in any medium, provided the original work is properly cited. 